\title{
Auswirkungen und Herausforderungen des EuGH-Urteils zu Pollen im Honig
}

\author{
Klaus-Dieter Jany
}

Online publiziert: 28 Juni 2012

(C) Bundesamt für Verbraucherschutz und Lebensmittelsicherheit (BVL) 2012

Der Europäische Gerichtshof (EuGH) musste in einem Ersuchen des Bayerischen Verwaltungsgerichtshofes im Verfahren des Imkers Bablok gegen den Freistaat Bayern zur Verkehrsfähigkeit von Honig mit Pollen aus gentechnisch veränderten Mais MON 810 Stellung beziehen. Der EuGH hat in seinem Urteilsspruch (C-442/09, 06.09.2011) mit der Einstufung von Pollen als Zutat in Honig, nicht Recht gesprochen, sondern Recht gesetzt. Diese Einstufung stellt einen Bruch in der bisherigen Rechtsauffassung zum Zutatenbegriff dar. Auf den ersten Blick betrifft das EuGH-Urteil nur Verkehrsfähigkeit und Kennzeichnung von Honig mit Pollen aus dem Mais MON 810; aber aus dem Urteil ist nicht eindeutig ableitbar, ob nur Pollen aus gentechnisch veränderten (gv-) oder auch Pollen aus konventionellen Pflanzen eine Zutat darstellen. Aus diesem Grund wird das EuGH-Urteil auch unterschiedlich interpretiert. Insbesondere Imkerverbände kommen zum Schluss, dass ausschließlich Pollen aus gv-Pflanzen als Zutat anzusehen seien und sie begrüßen das Urteil als einen Sieg über die Grüne Gentechnik. Die Auswirkungen des Urteils und das weitere Vorgehen werden auf nationaler und europäischer Ebene intensiv diskutiert. Auch wenn das Urteil rechtlich noch nicht umgesetzt ist, so wirken sich die Entscheidungen des EuGH über die An-/Verwendung von gentechnisch veränderten Organismen in der Agrar- und Lebensmittelwirtschaft aus. Sie betreffen auch Lebensmittelproduzenten und Imker, die Produkte aus konventionellen/

Professor Dr. K.-D. Jany (殴

Wadi-International-University, Hwash-Homs-Syria, Nelkenstraße 36, 76351 Linkenheim, Germany

e-mail: kd.jany@t-online.de traditionellen Organismen herstellen. EuGH-Entscheidungen haben in der Regel einen über den konkreten Fall hinausgehenden umfassenderen Charakter. Es ist ein richtungweisendes Urteil, dessen Folgen noch nicht absehbar sind.

Eindeutig ist das EuGH-Urteil darin, dass Pollen aus gv-Pflanzen eine EU-Zulassung als Lebensmittel (-zutat) aufweisen müssen. Damit ergibt sich, dass nur Honig mit Pollen aus voll umfänglich als Lebensmittel zugelassenen gv-Pflanzen verkehrsfähig und entsprechend der EU-Verordnung Nr.1829/2003 $\mathrm{zu}$ kennzeichnen ist. Bislang erfolgten HonigPollen-Analysen nur sporadisch und es liegen kaum Erfahrungen vor. Neue Herausforderungen ergeben sich für Wissenschaft und Überwachung. Validierte Verfahren zur Isolierung von Pollen aus Honig und zur Freisetzung von DNA für die entsprechenden PCR-Nachweisverfahren müssen entwickelt werden. Ansätze hierfür sind in der Arbeit von Waiblinger et al. (2012) in diesem Journal aufgezeigt. Die vorhandenen PCR-Methoden zur Detektion von gv-Pflanzen, mit denen die Überwachung große Erfahrungen hat, können weitgehend übernommen werden. Sie stoßen aber möglicherweise hier an ihre Grenzen, da im Honig im Allgemeinen nur geringe Mengen (bis ca. 0,5\%) an Pollen vorhanden sind. Für die Erfassung von Pollen nicht vollumfänglich zugelassener gv-Pflanzen ist die Empfindlichkeit der PCR-Verfahren sicherlich ausreichend, aber bei der Überprüfung des Schwellenwerts von 0,9\% hinsichtlich der Kennzeichnungsverpflichtung sind Schwierigkeiten $\mathrm{zu}$ erwarten. Zusätzlich ist vom EU-Gesetzgeber noch nicht abgeklärt, worauf sich die $0,9 \%$ beziehen sollen. Bezieht sich der Schwellenwert von $0,9 \%$ auf die Gesamtheit aller Pollen oder auf 
einzelne Pollen aus unterschiedlichen gv-Pflanzen? Falls sich der Bezugspunkt auf die Gesamtheit aller Pollen beziehen soll, so sind für die PCR-Erfassung aller im Honig vorkommender Pollen, spezifische Primer für Pflanzen zu entwickeln oder/und die mikroskopische morphologische Analyse der Pollen unterstützend in Betracht zu ziehen. Der Schwellenwert von $0,9 \%$ kann sich eigentlich nicht auf den Gesamtpollen im Honig beziehen, sondern, wie bereits für andere gv-Zutaten in Lebensmitteln angewandt, auch nur auf den gv-Pollen in Relation zur korrespondierenden nicht gv-Pflanze. Hier ist möglicherweise die Kombination von PCR-Verfahrem und Mikroskopie notwendig. Die Optimierung und Entwicklung neuer Kombinationsverfahren zur Erfassung von Pollen im Honig und zur Überprüfung der Kennzeichnungsverpflichtung sind notwendig.

Bei Ministerien und Überwachungsbehörden herrschen große Unsicherheiten über das Vorgehen zur Kennzeichnung von Honig mit Pollen aus gv-Pflanzen. Diese Problematik zeigt sich auch in dem Beitrag von Näumann et al. (2012). Deshalb hatte das EU-Urteil bislang nur Auswirkungen auf Honigimporte mit Pollen aus nicht voll umfänglich zugelassenen gv-Pflanzen, da solche Honige in der EU nun nicht mehr verkehrsfähig sind. In Deutschland wurden im Jahr 2010 ca. 23.000 t Honig erzeugt, wobei ca. die Hälfte im Rahmen der Direktvermarktung verkauft wird. Da in Deutschland keine gv-Pflanzen angebaut werden, sind deutsche Imker mit Direktvermarktung kaum betroffen. In Deutschland lag der Honigverbrauch 2010 bei ca 92.000 t, der Selbstversorgungsgrad liegt damit bei ca. $25 \%$. Der Rest, ca. $75 \%$, wird nach Deutschland, vorrangig aus Süd-, Mittelamerika (Argentinien, Mexiko), Kanada, Ukraine usw., importiert - und in diesen Ländern werden gv-Pflanzen angebaut. Deutsche Überwachungsberhörden haben seit September 2011 „Sonderprogramme“ zur Erfassung solcher Honige, inbesondere auf Pollen aus Mais MON 810 und aus gvRaps, durchgeführt. Im Kontext mit dem finanziellen Aufwand waren die Befunde mit nicht verkehrfähigen Honigen bescheiden, zumal im Vorfeld bereits Honig-exportierende Länder und Honigimporteure aufgrund des Abschlussberichtes des EuGH von Februar 2011 entsprechende kostenintensive Analysen durchgeführt hatten und positive Produkte vom Markt genommen hatten. Die Konsequenz allerdings ist, dass kanadischer Raps-Honig auf dem deutschen Markt nicht mehr erhältlich ist und Verbraucher Analysekosten teilweise mit dem Honigpreis bezahlen müssen. In Zukunft wird der Import von Honig aus Entwicklungs- und Schwellenländern erschwert werden oder kann nur mit Preisnachlässen erfolgen. Bemerkenswert aus den Analysen der Überwachung ist, dass in deutschen, auch in ökologisch erzeugten Honigen, DNA aus gv-Soja gefunden wurde. Offensichtlich setzen deutsche Imker Soja als Proteinquelle ein.

Für Verbraucher erbringen die kostenintensiven Analysen auf Pollen aus gv-Pflanzen noch keine Informationen, da die Schwellenwert-Regelung nicht geklärt ist und Honig mit Pollen aus voll umfänglich als Lebensmittel zugelassenen gv-Pflanzen verkehrsfähig und eine Kennzeichnung noch nicht durchführbar ist. Für Honig mit gv-Pollen, zugelassen oder nicht, besteht für Verbraucher keine gesundheitliche Gefährdung. Für den vorbeugenden gesundheitlichen Verbraucherschutz sind die Analysen nicht notwendig. Da die überwiegende Mehrheit der Verbraucher in Deutschland Lebensmittel, die als Produkte der Gentechnik gekennzeichnet sind, ablehnen, führt die Lebensmittelwirtschaft nicht nur Analysen für die direkte Vermarktung von Honig, sondern auch für Honige, die als Lebensmittelzutaten verwendet werden sollen, durch. Die Lebensmittelwirtschaft erfüllt nicht nur gesetzliche Auflagen, sondern sie möchte mit den Analysen das Vertrauen von Verbrauchern erhalten und sich vor „Anprangerungen" wappnen.

Der EuGH kommt zum Schluss, dass Pollen generell eine natürliche und unvermeidbare Zutat im Honig ist. Diese EuGH-Auffassung muss der europäische Gesetzgeber umsetzen. Auf ihn kommen ebenfalls große Herausforderungen und Aufgaben zu. Dies insbesondere vor dem Hintergrund, dass die Kommission das Lebensmittel Honig nun bestehend aus den Zutaten Honig und Pollen ansieht und entsprechend der Etikettierungsrichtline 2000/13/EG für Honig eine Zutatenliste zu erstellen sei. Die Zutatenliste soll unabhängig davon sein, ob der Pollen aus gv- oder konventionellen Pflanzen stammt.

Nach der Honigrichtlinie 2001/110/EG dürfen dem Honig keine Zutaten hinzugefügt werden. Mit der Einstufung von Pollen als Zutat muss der Gesetzgeber die Honigrichtlinie revidieren und Pollen als Zutat neu definieren. Andernfalls würden Imker und andere Inverkehrbringer von Honigprodukten stets gegen die Honigrichtlinie verstoßen.

Nach dem EuGH-Urteil müsste der Zutatenbegriff neu definiert werden. Nach der Auffassung des EuGH unterliegt Honig mit der Zutat „Pollen“ der Etikettierungsrichtline 2000/13/EG, Art. 6, Abs. 1 und den Anhängen I, II und III. Diese Auffassung lässt weitreichende Folgen für Lebensmittelwirtschaft und Imker erwarten. Dies würde besonders für Pollen 
aus allergieauslösenden Pflanzen, z. B. Sojabohne, Haselnuss, Lupine oder glutenhaltigem Getreide Bedeutung haben. Dies würde bedeuten, dass jede Honigcharge auf Pollen analysiert werden muss, und der enthaltene Pollen im Zutatenverzeichnis anzugeben ist. Für die Allergiekennzeichnung gibt es keinen Schwellenwert und auf die Allergenität bestimmter Pollen muss hingewiesen werden. Mit dem Nachweis von Pollen aus allergenen Pflanzen schließt sich wiederum der Kreis zum Einzelnachweis von Pollen auch aus gv-Pflanzen. Auf Honiganbieter, aber insbesondere auf Imker, kommen neue finanzielle Belastungen durch die notwendigen Analysen zu. Zertifikate/Zutatenlisten über Allergene und gvPollen werden sicherlich auch von Imkern aus dem fast gentechnikfreien Anbauland Deutschland abgefordert werden. Die Analysekosten übersteigen leicht den Erlös aus der Imkerei. Als Folge steht zu erwarten, dass viele Klein- und Hobbyimker die Imkerei aufgeben müssten. Das EuGH-Urteil könnte somit leicht in einen Pyrrhussieg des Hobbyimkers münden.
Der EU-Gesetzgeber ist nun gefordert, eine einheitliche Betrachtung $\mathrm{zu}$ den Auswirkungen des EuGH-Urteils zu Pollen im Honig herbeizuführen und entsprechende Verordnungen zu erarbeiten, die sich im Interesse von Landwirten, Imkern, Lebensmittelhandel und Verbrauchern praktikabel umsetzen lassen.

\section{References}

Waiblinger H-U, Ohmenhaeuser M, Meissner S, Schillinger M, Pietsch K, Goerlich O, Mankerts J, Lieske K, Broll H (2012) In-house and interlaboratory validation of a method for the extraction of DNA from pollen in honey. J Verbr Lebensm. doi: 10.1007/s00003-012-0774-Z

Näumann G, Waiblinger H-U, Bendiek J, Busch U (2012) Verkehrsfähigkeit von Honig mit Pollen gentechnisch veränderter Pflanzen. Der Sachstandsbericht Arbeitsgruppe “Überwachung gentechnisch veränderter Lebensmittel” des Arbeitskreises Lebensmittelsachverständigere der Länder und des Bundesamtes für Verbraucherschutz und Lebensmitelsicherheit (ALS), das Urteil des EuGH und seine möglichen Konsequenzen. J Verbr Lebensm. doi:10.1007| s00003-012-0779-7 